\title{
Kinerja Serapan Bunyi Komposit Ampas Tebu Berdasarkan Variasi Ketebalan dan Jumlah Quarter Wavelength Resonator terhadap Kinerja Bunyi
}

\author{
Restu Kristiani, ${ }^{*}$ Iwan Yahya ${ }^{\dagger}$ dan Harjana \\ Laboratorium Riset Akustik (iARG), Jurusan Fisika, Fakultas MIPA \\ Universitas Sebelas Maret, Ir. Sutami No.36 A Surakarta 57126
}

\begin{abstract}
Intisari
Telah dilakukan pengujian kinerja serapan bunyi dari komposit ampas tebu dikaitkan dengan pengaruh konfigurasi ketebalan dan konfigurasi quarter wavelength resonator. Pengujian kinerja dilakukan secara eksperimen menggunakan tabung impedansi dua mikrofon mengacu kepada prosedur ASTM E-1050-98. Dalam penelitian ini dilakukan variasi tiga dan enam konfigurasi resonator serta variasi air cavity yakni 1 , 2 , dan $3 \mathrm{~cm}$. Hasil penelitian menunjukkan bahwa komposit ampas tebu dengan konfigurasi enam resonator memiliki kinerja serapan bunyi terbaik. Adapun pengaruh ketebalan sampel adalah menggeser penyerapan bunyi efektif pada frekuensi rendah sementara penggunaan resonator efektif akan melebarkan rentang frekuensi penyerapan sehubungan dengan bertambahnya mekanisme redaman viskous bersamaan dengan mekanisme serapan resonasi.
\end{abstract}

\section{ABSTRACT}

\begin{abstract}
Sound absorption performance of bagasse composite has been conducted in associated with effect of thickness configuration and quarter wavelength resonator configuration. The testing was conducted experimentally refer to ASTM E-1050-98 standard procedure. In this measurement there are three variations and six resonator configuration and air cavity variations is 1,2 , and $3 \mathrm{~cm}$. The results showed that bagasse composite with six resonators configuration has the best sound absorption performance. As for sample thickness affect and shifts the effective absorption to lower frequency band while the use of resonators effectively widen sound absorption range due to increased viscous damping mechanism simultaneously with resonance absorption mechanism.
\end{abstract}

KATA KUNCI: bagasse, absorption coefficient, quarter wavelength resonators, impedance tube method.

\section{PENDAHULUAN}

Tebu (Saccharum officinarum) adalah tumbuhan jenis rumput-rumputan yang tumbuh di daerah tropis yang dimanfaatkan sebagai bahan baku pembuatan gula. Dari proses pengolahan gula tersebut dihasilkan limbah padat yakni ampas tebu (bagasse) yang mengandung serat sebanyak 35-40\% dari berat tebu. Ampas tebu dapat diolah lebih lanjut dan akan mempunyai nilai ekonomis yang tinggi, antara lain dimanfaatkan sebagai bahan dasar pembuatan produk kulit kapal [1], furfural [2], dan papan partikel [3].

Pemanfaatan lain dari bagasse disajikan pada makalah ini sebagai salah satu alternatif material penyerap bunyi dalam bentuk komposit. Pengaruh ketebalan sampel dan penggunaan konfigurasi resonator terhadap kinerja akustik komposit bagasse telah dikaji berdasarkan pengujian eksperimen.

\footnotetext{
*E-MAIL: serly_asshalihah@yahoo.com

${ }^{\dagger}$ E-MAIL: iwanyy@yahoo.com
}

Pilihan kajian atas dampak perubahan kinerja akustik komposit ampas tebu didasarkan pertimbangan bahwa komposit bagasse merupakan panel akustik dinding yang dapat diaplikasikan pada bangunan. Oleh karena itu, maka perilaku dan respon akustiknya menjadi sangat penting untuk memenuhi standar yang berlaku untuk panel penyerap bunyi yang digunakan untuk bangunan ISO 11654.

Penelitian karakteristik akustik banyak dilakukan seperti pada bahan komposit jerami dan kayu [4], serat daun teh segar [5], serat polyster daur ulang [6], serta papan wol kayu [7]. Penelitian karakteristik akustik dengan variasi ketebalan dilakukan pada alumunium busa [8], sampah industrial daun teh [9], serta jerami [10]. Hasil penelitian pada bahanbahan tersebut menunjukkan kinerja akustik khususnya koefisien serapan bunyi meningkat sejalan dengan penambahan ketebalan. Ketebalan dapat menggeser kinerja akustik pada rentang frekuensi rendah. Penambahan ketebalan adalah salah satu metode yang sangat lazim dilakukan untuk reduksi bising khususnya pada rentang frekuensi rendah.

Kinerja serapan bunyi adalah fungsi frekuensi yang umumnya dengan bertambahnya kinerja serapan bunyi efektif pada 
frekuensi tertentu dapat ditingkatkan salah satunya dengan menambahkan ketebalan [9] dan jumlah quarter wavelength resonator [11]. Ketebalan dan konfigurasi resonator menjadi pilihan kajian yang dominan dalam makalah ini didasarkan pertimbangan bahwa pengaruhnya dapat meningkatkan kinerja serapan bunyi. Karakteristik batas serapan pada sampel dapat dioptimalkan dengan tiga parameter yakni panjang resonator untuk menentukan frekuensi utama dimana bunyi diserap, jari-jari resonator dan porositas dari sampel untuk menentukan ketinggian dan lebar dari puncak batas serapan [11]. Penelitian sebelumnya telah menunjukkan bahwa bunyi yang menyebar dari panel dapat direduksi dengan aplikasi tabung resonator $[12,13]$. Pilihan ragam konfigurasi jumlah resonator di atas didasarkan pada penelitian terdahulu antara lain Wang et al [14] yang menyajikan kajian yang bersifat teoritik atas respon array resonator di dalam pipa yang mana diperoleh hasil bahwa pemakaian resonator ini dapat memberikan kemampuan reduksi bising yang lebih efektif dibandingkan dengan resonator tunggal.

Pada penelitian ini, dilakukan pengukuran koefisien serapan bunyi sampel komposit ampas tebu dengan variasi ketebalan dan jumlah quarter wavelength resonator. Metode yang digunakan adalah metode tabung impedansi dua mikrofon sesuai dengan standar pengukuran ASTM E 1050-98 [15].

\section{METODOLOGI}

\section{Pembuatan Model Komposit Ampas Tebu}

Konfigurasi sampel yang digunakan dalam penelitian disajikan pada Gambar 1. Strukturnya terbuat dari komposisi ampas tebu, lem PVAC dan air. Pada pembuatan sampel digunakan perbandingan komposisi massa. Perbandingan komposisi massa yang digunakan berdasarkan beberapa kali eksperimen dengan menggunakan komposisi massa yang berbeda. Dari eksperimen tersebut ditentukan perbandingan massa yang sesuai berdasarkan hasil yang didapat dari segi kerapatan, kerekatan dan proses pengepresannya. Perbandingan komposisi massa ampas tebu : lem fox : air adalah 1 : $3: 1,5$. Bahan yang sudah tercampur kemudian dimasukkan ke dalam cetakan. Proses pengepresan dilakukan selama sehari, kemudian sampel dikeluarkan dari cetakan dan dibiarkan mengering secara alami. Setelah sampel kering, sampel dipotong dengan diameter $\pm 2,9 \mathrm{~cm}$. Hal ini dimaksudkan agar sampel dapat tepat dimasukkan kedalam tabung impedansi untuk diukur koefisien serapan bunyinya.

Pengujian komposit dengan penambahan resonator dilakukan dengan memberikan tambahan resonator dengan variasi lubang yaitu tiga lubang pada sampel A1, A3 dan A5, dan enam lubang pada sampel A2 dan A4. Dimensi kelima sampel ditunjukkan Tabel I.

\section{Pengujian Koefisien Serapan Bunyi}

Pengujian koefisien serapan bunyi dari model komposit ampas tebu ditempuh dengan prosedur pengujian tabung

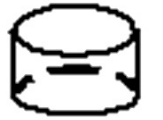

(a)

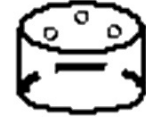

(b)

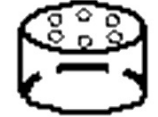

(c)
Gambar 1: Konfigurasi sampel a) komposit ampas tebu, b) komposit ampas tebu dengan quarter wavelength resonator tiga lubang, c) komposit ampas tebu dengan quarter wavelength resonator enam lubang.

TABEL I: Data massa, diameter, tebal, dan volume.

\begin{tabular}{cccc}
\hline \hline $\begin{array}{c}\text { Kode } \\
\text { Sampel }\end{array}$ & $\begin{array}{c}\text { Massa } \\
(\mathrm{gram})\end{array}$ & $\begin{array}{c}\text { Diameter } \\
(\mathrm{cm})\end{array}$ & $\begin{array}{c}\text { Tebal } \\
(\mathrm{cm})\end{array}$ \\
\hline A1 & 3,69 & 2,92 & 1,90 \\
$\mathrm{~A} 2$ & 3,73 & 2,91 & 1,70 \\
$\mathrm{~A} 3$ & 2,37 & 2,92 & 1,10 \\
$\mathrm{~A} 4$ & 1,76 & 2,92 & 1,00 \\
$\mathrm{~A} 5$ & 1,70 & 2,92 & 0,80 \\
\hline \hline
\end{tabular}

impedansi dua mikrofon. Metode ini mengacu pada prosedur standar ASTM E 1050-98 yang berbasis analisis fungsi transfer terhadap sinyal oleh dua mikrofon [16]. Set up alat disajikan dalam Gambar 2.

Bunyi berupa random noise dibangkitkan dengan Generator B\&K 3160-A-042 yang kemudian diperkuat dengan amplifier B\&K 2716C. Sebagian gelombang datang akan diserap dan sebagian dipantulkan kembali. Gelombang datang dan gelombang pantul akan ditangkap dengan dua buah mikrofon B\&K 4187. Setelah diperkuat, sinyal yang ditangkap oleh kedua mikrofon akan diteruskan ke 4-ch mikrofon module B\&K 3160-A-042 dan dilakukan analisis frekuensi untuk mendapatkan fungsi respon frekuensi $\mathrm{H}_{12}$, fungsi respon frekuensi gelombang datang $\mathrm{H}_{i}$, dan fungsi respon frekuensi gelombang pantul $\mathrm{H}_{r}$. Pada Gambar 3 merupakan skema tabung impedansi dua mikrofon. Untuk mendapatkan nilai digunakan metode transfer function [17].

Tekanan bunyi dirumuskan :

$$
\begin{aligned}
& P_{1}=p_{i} e^{j k(h+s)}+p_{i} e^{-j k(h+s)} \\
& P_{2}=p_{i} e^{j k h}+p_{i} e^{-j k h}
\end{aligned}
$$

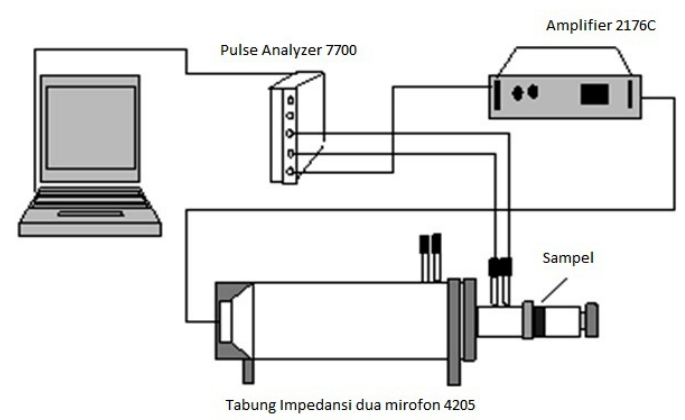

Gambar 2: Konfigurasi dalam pengujian koefisien serapan bunyi dengan ASTM E 1050-98. 


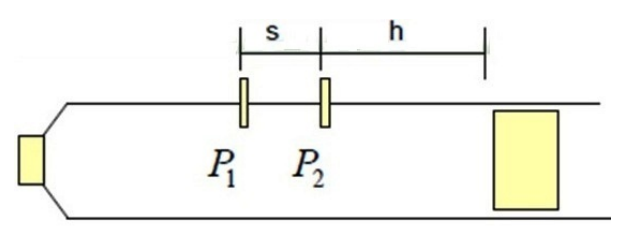

Gambar 3: Skema tabung impedansi dua mikrofon. [18]:

Transfer function diantara dua sinyal mikrofon menjadi

$$
H_{12}=\frac{P_{2}}{P_{1}}=\frac{e^{j k h}+R e^{-j k h}}{e^{j k(h+s)}+e^{-j k(h+s)}}
$$

Koefisien refleksi dirumuskan:

$$
R=\frac{H_{12}-e^{-j k s}}{e^{j k s}-H_{12}} e^{j 2 k(h+s)}
$$

dengan $\mathrm{k}$ adalah bilangan gelombang, $\mathrm{h}$ dan s berturut-turut merupakan jarak mikrofon pertama ke sampel uji dan jarak antar mikrofon.

Dengan menggunakan nisbah impedansi ternormalisasi, maka diperoleh:

$$
\frac{z}{\rho c}=\frac{1+R}{1-R}
$$

sehingga dapat dihitung koefisien serapan bunyi:

$$
\alpha=1-|R|^{2}
$$

Pengolahan data pada eksperimen dikerjakan dengan komputer menggunakan perangkat lunak B\&K Labshop Software versi 16 serta Pulse Material Testing yang memang digunakan untuk analisis serapan akustik. Grafik yang disajikan diolah menggunakan Origin 8.

\section{HASIL DAN PEMBAHASAN}

\section{Konfigurasi komposit ampas tebu dengan variasi ketebalan}

Pada variasi ketebalan ini menggunakan konfigurasi sampel Gambar 1 (a). Hasil pengujian konfigurasi komposit ampas tebu dengan variasi ketebalan disajikan pada Gambar 4 yang menyajikan nilai koefisien serapan bunyi terhadap frekuensi dengan bentang frekuensi 250-4000 Hz. Pada Gambar 4, nilai puncak koefisien serapan bunyi pada sampel dengan ketebalan $1,90 \mathrm{~cm}, 1,70 \mathrm{~cm}, 1,10 \mathrm{~cm}, 1,00 \mathrm{~cm}$, dan $0,80 \mathrm{~cm}$ berturutturut adalah 0,52 pada frekuensi $1000-1352 \mathrm{~Hz}, 0,43$ pada frekuensi $968-1224 \mathrm{~Hz}, 0,50$ pada frekuensi $1500-1700 \mathrm{~Hz}$, 0,57 pada frekuensi $2096-2376 \mathrm{~Hz}$, dan 0,56 pada rentang frekuensi $2056-2320 \mathrm{~Hz}$.

Terdapat perbedaan pengaruh ketebalan pada penelitian ini dengan penelitian Ersoy dan Kucuk [9] yakni bahan sampah

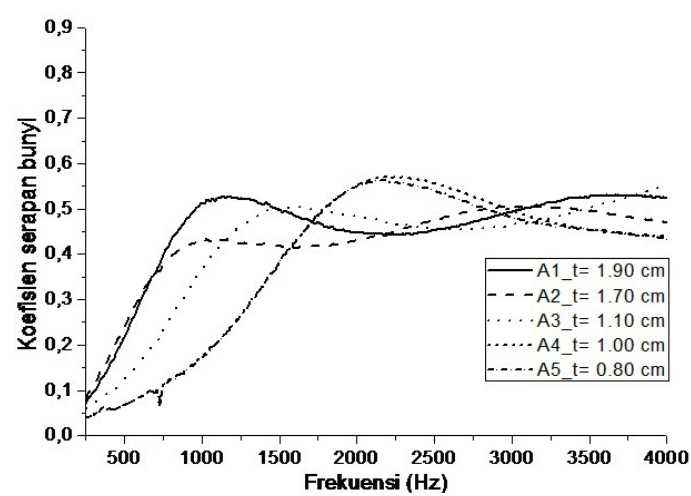

Gambar 4: Grafik koefisien serapan bunyi dengan variasi ketebalan.

industri daun teh. Pada bahan sampah industri daun teh, semakin tebal sampel maka koefisien serapan bunyi semakin meningkat. Sedangkan pada penelitian ini, nilai koefisien serapan bunyi tertinggi pada sampel dengan ketebalan yang lebih tipis. Hal ini disebabkan adanya perbedaan kerapatan sampel. Pada penelitian ini komposit ampas tebu mendapatkan perlakuan tekanan yang belum bisa diukur besarnya, porositas pada komposit yang cukup besar memberikan kontribusi bagi penyerapan bunyi yang baik pada frekuensi tinggi.

Pada sampel A1 dan sampel A2 dengan ketebalan 1,90 cm dan $1,70 \mathrm{~cm}$ mempunyai rentang frekuensi yang lebih lebar dibandingkan dengan sampel A3, A4 dan sampel A5 pada saat nilai koefisien serapan bunyinya 0,4. Hasil tersebut sejalan dengan teori Everest [15] dengan ketebalan sampel akan menggeser frekuensi ke frekuensi rendah dengan nilai koefisien serapan bunyi yang tinggi. Pada Gambar 4 dapat diketahui bahwa semakin tebal sampel maka koefisien serapan bunyi semakin bergeser ke frekuensi yang lebih rendah.

\section{Konfigurasi komposit ampas tebu dengan quarter wavelength resonator tiga lubang dan enam lubang}

Resonator dapat mempengaruhi nilai koefisien serapan bunyi suatu material. Pada penelitian ini, terjadi peningkatan nilai koefisien serapan bunyi pada komposit ampas tebu yang telah diberi resonator. Pada Gambar 5 terlihat peningkatan nilai koefisien serapan bunyi dengan quarter wavelength resonator tiga lubang dan enam lubang. Nilai koefisien serapan bunyi lebih tinggi saat resonator enam lubang. Pada Gambar 5, menunjukkan bahwa konfigurasi resonator dengan enam lubang merupakan kinerja serapan bunyi terbaik. Hasil tersebut sejalan dengan penelitian Wang and Mak [14] dimana pemakaian resonator jamak dapat memberikan kinerja serapan yang baik. Hal ini disebabkan penggunaan resonator terakumulasi sebesar dua kali lipat pada konfigurasi resonator tiga lubang sehingga akan efektif meningkatkan penyerapan bunyi karena meningkatnya mekanisme redaman viskous. Redaman viskous adalah mekanisme peredam paling umum digunakan untuk analisis getaran. Ketika sistem mekanik bergetar dalam medium gas, perlawanan yang diakibatkan oleh gas bergerak ke arah material sehingga terjadi perubahan energi, dari energi getar menjadi energi panas. 


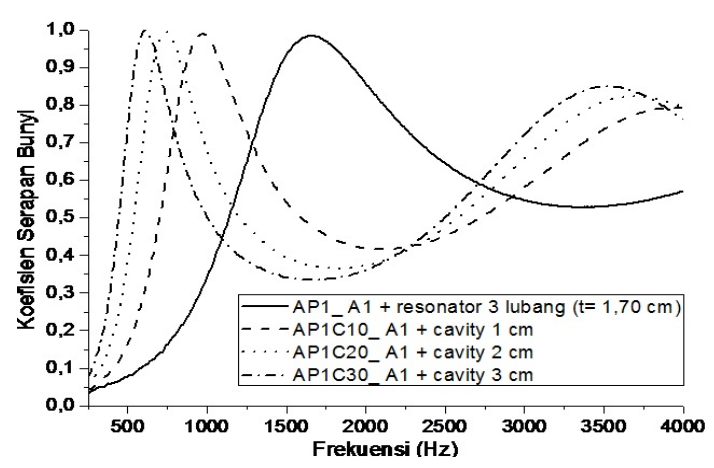

(a)

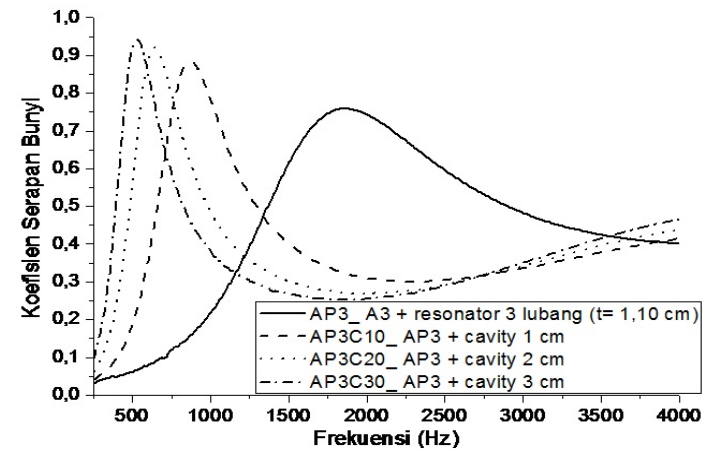

(c)

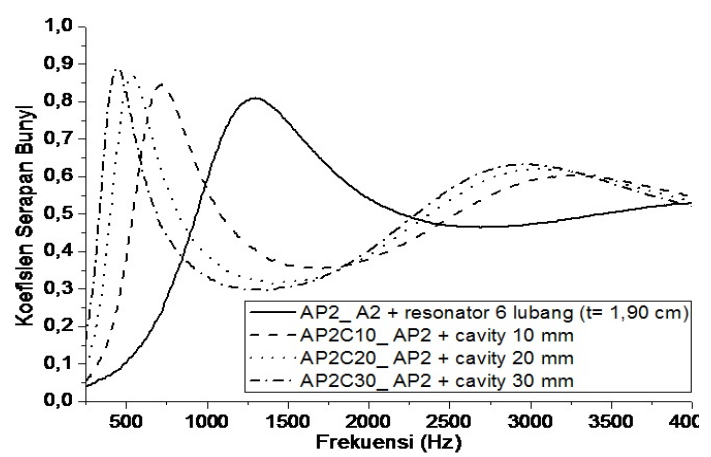

(b)

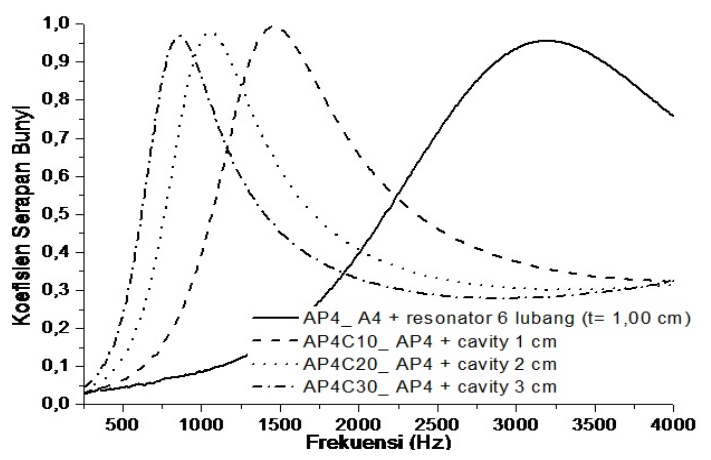

(d)

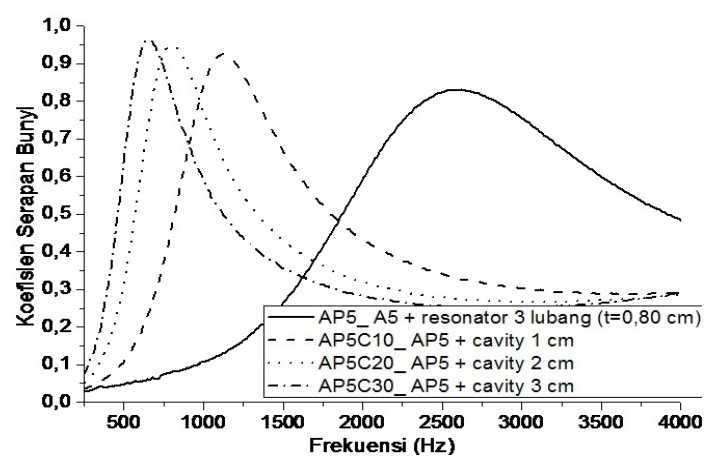

(e)

Gambar 5: Grafik koefisien serapan bunyi dengan variasi quarter wavelength resonator (b) dan (d) 6 lubang; (a), (c) dan (e) 6 lubang.

Nilai koefisien serapan bunyi juga dipengaruhi oleh diameter lubang pada resonator karena mekanisme penyerapan resonansi akan meningkat. Dalam penelitian ini menggunakan diameter lubang $0,5 \mathrm{~cm}$. Semakin besar diameter lubang maka akan semakin besar kemungkinan gelombang bunyi menumbuk permukaan lapisan porous, dengan demikian maka energi bunyi yang diserap juga akan semakin banyak sehingga nilai koefisien serapan bunyi akan meningkat. Selain itu koefisien serapan bunyi dapat meningkat karena pada konfigurasi quarter wavelength resonator ini terjadi redaman viskous bersamaan dengan mekanisme resonansi.

Pada Gambar 5, ketika konfigurasi resonator ditambahkan air cavity maka terjadi perubahan respon resonator ke bentang frekuensi yang lebih rendah. Hal ini disebabkan air cavity dianalogikan sebagai massa dalam osilator dan resonator sebagai pegasnya. Konfigurasi ini memberikan peluang yang lebih baik untuk terjadinya penyerapan energi bunyi melalui
TABEL II: Hasil Penelitian Nilai Koefisien Serapan Bunyi.

\begin{tabular}{lrrrrr}
\hline \hline Sampel & \multicolumn{5}{c}{ Frekuensi (Hz) } \\
& 250 & 500 & 1000 & 2000 & 4000 \\
\hline A1 & 0,08 & 0,24 & 0,43 & 0,43 & 0,47 \\
A2 & 0,07 & 0,22 & 0,51 & 0,45 & 0,52 \\
A3 & 0,06 & 0,13 & 0,37 & 0,48 & 0,55 \\
A4 & 0,04 & 0,07 & 0,17 & 0,55 & 0,44 \\
A5 & 0,04 & 0,07 & 0,17 & 0,55 & 0,43 \\
AP1 & 0,04 & 0,11 & 0,60 & 0,54 & 0,53 \\
AP2 & 0,03 & 0,08 & 0,34 & 0,86 & 0,57 \\
AP3 & 0,03 & 0,06 & 0,22 & 0,74 & 0,40 \\
AP4 & 0,03 & 0,04 & 0,09 & 0,40 & 0,76 \\
AP5 & 0,03 & 0,05 & 0,11 & 0,60 & 0,50 \\
\hline \hline
\end{tabular}

mekanisme redaman viskous karena terdapat tiga dan enam 
TABEL III: Nilai Koefisien Standar Serapan Bunyi.

\begin{tabular}{lccccc}
\hline \hline Kelas & \multicolumn{5}{c}{ Frekuensi (Hz) } \\
& 250 & 500 & 1000 & 2000 & 4000 \\
\hline $\mathrm{A}$ & 0,70 & 0,90 & 0,90 & 0,90 & 0,80 \\
$\mathrm{~B}$ & 0,60 & 0,80 & 0,80 & 0,80 & 0,70 \\
$\mathrm{C}$ & 0,40 & 0,60 & 0,60 & 0,60 & 0,50 \\
$\mathrm{D}$ & 0,10 & 0,30 & 0,30 & 0,30 & 0,20 \\
$\mathrm{E}$ & 0,00 & 0,17 & 0,17 & 0,17 & 0,05 \\
\hline \hline
\end{tabular}

elemen massa yang berayun di dalam struktur leher resonator.

Nilai koefisien serapan bunyi minimum bahan untuk dapat dikategorikan sebagai peredam bunyi menurut ISO 11654:1997 untuk Acoustical Sound Absorbers For Use In Buildings-Rating of Sound Absorption sebesar 0,15 pada rentang frekuensi 500-4000 Hz [19]. Hasil pengujian sampel disajikan pada Tabel II dengan nilai koefisien standar serapan bunyi ditunjukkan dalam Tabel III.
Komposit ampas tebu yang dikembangkan memenuhi syarat ISO 11654 yang berada pada kelas D dimana nilai koefisien serapan akustik berkisar antara 0,10 hingga 0,30 pada rentang frekuensi $250-4000 \mathrm{~Hz}$.

\section{SIMPULAN}

Berdasarkan analisis di atas dapat dikemukakan kesimpulan bahwa ketebalan sampel mempengaruhi nilai koefisien serapan akustik yang secara efektif bergeser pada frekuensi rendah, sementara penggunaan resonator secara efektif dapat menyebabkan nilai koefisien serapan bunyi meningkat dengan rentang frekuensi yang lebih lebar sehubungan dengan bertambahnya mekanisme redaman viskous bersamaan dengan mekanisme serapan resonansinya. Kinerja akustik terbaik dapat dicapai pada konfigurasi model $\mathrm{C}$ dengan penambahan quarter wavelength resonator dengan enam lubang.
[1] H. Yudo, dan S. Jatmiko, KAPAL, 5 (2), 95-101 (2008).

[2] A. Wijanarko, J.A. Witono., dan M.S. Wiguna, Journal of the Indonesian Oil and Gas Community (ISSN:1829-9466), 1, 1-8 (2006).

[3] R. Widyorini, et al., J. Wood Sci., 51, 648-654 (2005).

[4] H.S. Yang, D.J. Kim, and H.J. Kim, Bioresource Technology, 86, 117-121 (2003).

[5] M. Fukuhara, et al., JARQ, 39, 45-49 (2005).

[6] Y. Lee, and J. Changwan, AUTEX Research Journal, 3 (2), 78-84 (2003).

[7] L. Karlinasari, $d k k$. Jurnal Ilmu dan Teknologi Hasil Hutan, 4 (1), 8-13 (2011).

[8] O. Jae-Eung, et al., KSME Inernational Journal, 12, 1017-1025 (1998).

[9] S. Ersoy, and H. Kucuk., Applied Acoustics, 70, 215-220 (2009).

[10] C.E. Mediastika, DIMENSI (Journal of Architecture and Built Environment), 36 (2), 127-134 (2008).

[11] M.H.C. Hannink, Acoustic resonator for the reduction of sound radiation and transmission, $\mathrm{PhD}$. Thesis, University of Twente, Enschede, the Netherland, 2007.

[12] M.H.C. Hannink, et al., Application of acoustically tuned res- onators for the improvement of sound insulation in aircraft, Proceeding of Internoise, Rio de Janeiro, Brazil, 2005.

[13] M.H.C. et al., A finite element approach to the prediction of sound transmission through panels with acoustic resonators, Proceeding of ICSV13, Vienna, Austria, 2006.

[14] X. Wang, and C. Mak, Journal Acoustical Society of America, 131, 1-3 (2012).

[15] F.A. Everest, Master Handbook of Acoustics (Fourth Edition, United Stated of America, McGraw-Hill Companies, 2001).

[16] ASTM E 1050-98, Standard Test Method for Impedance and Absorption of Acoustical Materials Using Tube, Two Microphones and A Digital Frequency Analysis System, American Society for Testing and Materials (1998).

[17] P. Law Lok Yin, A Study of Perforated Panels for Sound Absorption, Thesis, The Hongkong Polytechnic University, 2003.

[18] F.P. Mechel, Formula of Acoustics ( $2^{\text {nd }}$ Edition, SpringerVerlag, Berlin, 2008).

[19] STD ISO 11654, Acoustics - Sound absorbers for use in buildings - Rating of sound absorption, English: The International Organization For Standardization, 1997. 